\title{
Editorial
}

\section{Building Bridges Between Social Work and Prenatal Psychology}

Source: Clinical Social Work and Health Intervention Pages: $6-7$
Volume: 12

Cited references: 4
Issue: 4

CSWHI 2021; 12(4): 6 - 7; DOI: 10.22359/cswhi_12_4_13 C Clinical Social Work and Health Intervention

\section{In Memoriam Prof. MUDr. PhDr. Peter G. Fedor-Freybergh, DrSc., Dr.h.c.}

This issue of Clinical Social Work and Health Intervention is dedicated to deceased co-founder of our Journal and President of the International Society of Prenatal and Perinatal Psychology and Medicine, Director of the First Department of Perinatal Psychology and Medicine, Honorary Doctor and holder of Honorary Degrees and Medals of multiple Universities in Poland, Czechoslovakia, Italy, Malaysia, etc, Doctor of Medicine and Psychology and Editor in chief of four Medical Journals: Acta Neurosa Superioris Rediviva, Neuroendocrinology Letters, Clinical Social Work and Health Intervention and Int. Journal of Prenatal and Perinatal Psychology and Medicine (1-4). Together with his spouse Lili Maas, ArtD., who added to the exact science, arts and her heart and love, all of those Journals were not only reading of naked facts and theories, or science but both were teaching us to accept psychology, social work and medicine as art culture and love, what is more than science and knowledge, more than facts. (From the letter of St. Paul and two letters of St. Peter, New Testament)

Among his students and Fellows, Professors and Associate Professors, two were Ministers of Health in the EU and outside of EU. They are not only his successors but real constructors of bridges between medicine, psychology, social work, theology and arts.

In an era of health threats and social disasters, psychological deprivation and absence of solidarity, he came with his spirit at the right time, and he stays with his spirit still, and long, long into the future. 
Therefore, we do not wish only ,requiem aeternam dona tibi Domine Petrus et lux perpetua luceat tibi“, („Lord, grant you Peter eternal rest and may perpetual light shine on you") but also Peter, please stay with us with your Mystery and Art and Love Forever! We love you but we also need you and remember your message „Turris fortis mihi Deus“ („God is my strong tower").

Claus Muss Integr Group Appl Preventive Medicine Zurich, Switzerland Joseph Miklosko St. Elizabeth University Bratislava, Slovakia

Marketa Vladarova St. John Institute Pribram, Czech Republic Selvaraj Subramaniam SAAARM Kuala Lumpur, Malaysia Michael Olah IGAP Vienna, Austria - Co Editor CSW

\section{References}

1. Acta Nervosa Superior Rediviva Vol.8-2021

2. Neuroendocrinology Letters, www.nel.edu eu.

3. Clinical social work and health Intervention Vol. 12.2021.4

4. Int. Journal of Prenatal \& Perinatal Psychology \& Medicine Vol. 35.2021 